\title{
Contrast as a function of component duration*
}

\author{
CHARLES P. SHIMP and RONALD L. MENLOVE $\dagger$ \\ University of Utah, Salt Lake City, Utah 84112
}

\begin{abstract}
Behavioral contrast was studied as a function of the duration of two components of a multiple schedule: a constant component (a variable-interval 1-min schedule) alternated either every 5 sec or every $180 \mathrm{sec}$ with a variable component (a variable-interval $1-\mathrm{min}$ or an extinction schedule). The rate at which three pigeons pecked for food during the constant component revealed a strong reinforcement interaction, when component duration was $5 \mathrm{sec}$, but not when component duration was 180 sec. The results add to previous findings that component duration in concurrent and concurrent-like schedules of reinforcement affects both preference for a component and reinforcement interactions between components.
\end{abstract}

In a successive discrimination paradigm called a multiple schedule, two different component schedules alternate. The percentage of all responses that are in one component is a function of the percentage of reinforcements delivered during that component (Reynolds, 1963). This function itself depends on the duration of the components (Shimp \& Wheatley, 1971; Tod orov, 1972; Killeen, 1972). Specifically, as component duration is shortened, the way in which responding is distributed between the two components approaches the results obtained when the two components are arranged concurrently. One can look at the rate of responding within a single component as well as at the way responses are distributed between components. Response rate in one component decreases as reinforcement rate in the other component increases (Reynolds, 1963). The purpose of the present experiment was to determine whether the magnitude of this reinforcement interaction between components in a multiple schedule depends on the duration of the components.

\section{METHOD}

\section{Subjects}

Three White Carneaux pigeons were maintained at approximately $80 \%$ of their free-feeding weights. The Ss previou sly had served in a variety of experiments.

\section{Apparatus}

Three Lehigh Valley Electronics three-key pigeon chambers were interfaced to a Digital Equipment Corporation PDP-8/E computer. Only the left and right keys were used in each chamber. White noise helped to mask extraneous sounds.

\section{Procedure}

The reinforcement schedule was a multiple schedule with alternating components, $\mathrm{A}$ and $\mathrm{B}$. Component $\mathrm{A}$ was a constant variable-interval (VI) 1-min schedule, and Component $B$ was, in different conditions, a VI 1-min or extinction (EXT) schedule.

*This research was supported in part by NIMH Grant 16928 and a fellowship from the Center for Advanced Study in the Behavioral Sciences to the first author. The authors wish to thank Candace Lindsey and Gwendolyn Ryan for their assistance in conducting the experiment.

+ Now at the University of Delaware.
Components $\mathrm{A}$ and $\mathrm{B}$ alternated either every $5 \mathrm{sec}$ or every $180 \mathrm{sec}$. The details of this procedure are reported below.

\section{Stimuli}

During Component A, the constant component, the left response key appeared red and the right key was dark. During Component B, the variable component, the left key was dark and, if a reinforcement was scheduled for the next peck in the variable component, the right key was green; otherwise, the right key was dark. Thus, reinforcements in the variable component were signaled by the green keylight. In its absence, responding during the variable component was negligible, thereby eliminating any potential difficulties involving response induction from the variable to the constant component.

A keylight was turned off for $0.1 \mathrm{sec}$ after every keypeck to provide response feedback, and during reinforcement, only a light over the food hopper was turned on.

\section{Component Schedules}

When a VI schedule arranged a reinforcement in a component, the reinforcement remained available until it was collected: if an available reinforcement was not collected before the end of a component, it was not cancelled and was available for the first peck the next time that component appeared.

Table 1 shows which schedule, VI 1 min or EXT, was arranged in the variable component in which conditions. Note that the keys were always dark in the variable component when its schedule was EXT.

\section{Component Alternation}

Components A and B alternated and were of the same duration in a given condition. Table 1 shows the component duration in each condition.

\section{Other Contingencies}

Reinforcement consisted of 2.5 -sec access to mixed grain. The 1-h sessions were conducted 6 days per week. Conditions were terminated when the response rate in the constant component appeared stable over several days.

\section{RESULTS}

Table 1 shows the response rate in the constant component for each $\mathrm{S}$ in each condition. The principal changes in response rate are clearly revealed by averages over pairs of conditions with identical schedules: 1 and 5,2 and 6,3 and 8 , and 4 and 7. From these averages of the data in Table 1, one finds that response rate in Component A changed from 38 to 28 , from 75 to 85 , 
Table 1

Experimental Conditions

\begin{tabular}{|c|c|c|c|c|c|c|}
\hline \multirow{2}{*}{$\begin{array}{l}\text { Condi- } \\
\text { tions }\end{array}$} & \multirow{2}{*}{$\begin{array}{c}\text { Number } \\
\text { of } \\
\text { Days }\end{array}$} & \multirow{2}{*}{$\begin{array}{l}\text { Compo- } \\
\text { nent } \\
\text { Duration } \\
\text { (Sec) }\end{array}$} & \multirow{2}{*}{$\begin{array}{l}\text { Schedule in the Variable } \\
\text { Component Alternating With } \\
\text { a VI 1-Min Schedule in } \\
\text { the Constant Component }\end{array}$} & \multicolumn{3}{|c|}{$\begin{array}{l}\text { Responses Per Minute in } \\
\text { the Constant Component }\end{array}$} \\
\hline & & & & Bird 1 & Bird 2 & Bird 3 \\
\hline 1 & 23 & 180 & VI $1 \mathrm{Min}$ & 33 & 66 & 31 \\
\hline 2 & 22 & 180 & EXT & 32 & 83 & 31 \\
\hline 3 & 46 & 5 & VI $1 \mathrm{Min}$ & 44 & 79 & 35 \\
\hline 4 & 38 & 5 & EXT & 69 & 120 & 41 \\
\hline 5 & 12 & 180 & VI 1 Min & 43 & 83 & 19 \\
\hline 6 & 13 & 180 & EXT & 23 & 87 & 26 \\
\hline 7 & 33 & 5 & EXT & 29 & 102 & 47 \\
\hline 8 & 18 & 5 & VI 1 Min & 29 & 82 & 31 \\
\hline
\end{tabular}

and from 25 to 28, for Birds 1, 2, and 3, respectively, when the variable component schedule changed from VI to EXT, for 180-sec components. Two of three Ss showed an increased response rate. It has been noted previously that for the fairly high Component A reinforcement rate employed here, a reinforcement interaction might not appear (Reynolds, 1963). The corresponding average response rate changes for 5 -sec components were: from 37 to 49 , from 81 to 111 , and from 33 to 44, for Birds 1, 2, and 3, respectively. All three Ss clearly showed a rate increase for 5 -sec components.

The difference in the magnitude of the reinforcement interaction with 5- and 180-sec components becomes strikingly clear if one looks at the percent change from the baseline mult VI VI response rate that was produced by the mult VI EXT schedule. For 180-sec components, these percent changes were $-26,+13$, and +12 , for Birds 1,2 , and 3 , respectively. The average percent change was zero for 180 -sec components. But for 5 -sec components, the percent change was $+32,+37$, and +33 , for Birds 1 , 2 , and 3, respectively. For 5-sec components, responding in the constant component was elevated on the average to a value of more than one-third above baseline.

\section{DISCUSSION}

The magnitude of reinforcement interaction in a multiple schedule was shown to depend on the duration of the alternating components: interaction was greater with shorter component durations. This result is qualitatively consistent with several theoretical viewpoints (Herrnstein, 1970; Rachlin, 1973). The result is consistent also with the finding by Nevin and Shettleworth (1966) and by Menlove (1972) of transient contrast in multiple schedules. These investigators found a greater reinforcement interaction near the beginning of a $180-\mathrm{sec}$ component than later in the component.

With short component durations, such as $5 \mathrm{sec}$, the distribution of responses between components in multiple schedules resembles the corresponding distribution in concurrent schedules (Shimp \& Wheatley, 1971; Todorov, 1972; Killeen, 1972). And in at least some concurrent paradigms, component duration affects preference (Stubbs \& Plisk off, 1969) and the magnitude of reinforcement interactions (Shimp \& Hawkes, 1974). Component duration is a variable which importantly affects behavior in concurrent and concurrent-like schedules of reinforcement: it seems doubtful that a generally valid quantitative description of concurrent and concurrent-like schedules can be developed without consideration of the effects of component duration. At present, we are unaware of any account of performances maintained by concurrent or concurrent-like schedules that takes account of the effects of component duration.

\section{REFERENCES}

Herrnstein, R. J. On the law of effect. Journal of the Experimental Analy sis of Behavior, 1970, 13, 243-266.

Killeen, P. A yoked-chamber comparison of concurrent and multiple schedules. Journal of the Experimental Analysis of Behavior, 1972, 18, 13-22.

Menlove, $R$. L. Local patterns of responding maintained by concurrent and multiple schedules. Unpublished PhD dissertation, University of Utah, 1972.

Nevin, J. A., \& Shettlew orth, S. J. An analy sis of contrast effects in multiple schedules. Journal of the Experimental Analysis of Behavior, 1966, 9, 305-315.

Rachlin, H. C. Contrast and matching. Psychological Review, $1973,80,217-234$.

Reynolds, G. S. Some limitations on behavioral contrast and induction during successive discrimination. Journal of the Experimental Analy sis of Behavior, 1963, 6, 131-139.

Shimp, C. P., \& Hawkes, L. Time-allocation, matching, and contrast. Journal of the Experimental Analysis of Behavior, 1974 , in press.

Shimp, C. P., \& Wheatley, K. L. Matching to relative reinforcement frequency in multiple schedules with a short component duration. Journal of the Experimental Analysis of Behavior, 1971, 15, 205-210.

Stubbs, D. A., \& Pliskoff, S. S. Concurrent responding with fixed relative rate of reinforcement. Journal of the Experimental Analy sis of Behavior, 1969, 12, 887-895.

Todorov, J. C. Component duration and relative response rates in multiple schedules. Journal of the Experimental Analysis of Behavior, 1972, 17, 45-49.

(Received for publication March 16, 1974.) 